\title{
Laboratory Information System-Electronic Health Record Interconnection, Usage and Functionality in Ambulatory Care Settings
}

Hyacinthe $\mathbf{G N}^{*}$ and Mathieson $\mathrm{K}$

AT Still University, College of Graduate Health Studies, 5850 E. Still Circle, Mesa, AZ 85206

\begin{abstract}
Background: Laboratory information maximizes effective delivery of care by allowing physicians and other providers to make appropriate diagnostic and therapeutic decisions. Studies exploring the Electronic Health Record (EHR) interconnection with the laboratory information system (LIS) through data processing, reviewing, and sharing capabilities among ambulatory care providers are scarce.
\end{abstract}

Aim: The aim of this study was to explore the use of electronic laboratory services through the EHR-LIS interconnectivity to access patient laboratory data in meaningful way. This study was further used to evaluate the relationship between practice characteristics and meaningful usage of laboratory functionalities.

Method: Using a nationally representative sample of 44,296 physician responses from National Ambulatory Medical Care Survey (NAMC) data, this study used descriptive statistics to first determine the level of meaningful usage of the EHR-LIS functionalities among ambulatory care physicians. Logistic regression was then used to assess potential effects of factors, such as physician specialty, practice type, practice geographical region, and ownership status on usage of the EHR-LIS functions.

Results: More than two-third of physicians used the EHR-LIS meaningfully. The strongest positive associations $(\mathrm{OR}=2.64$ and 2.42) were found between practice type (solo, non-solo) and electronic reviewing and sharing of laboratory test results with ambulatory physicians in practice group. On the other hand, practice region and ownership status negatively influenced $(\mathrm{OR}=0.79,0.94$, and 0.77$)$ the electronic sharing of tests results with physicians outside practice groups.

Conclusion: Practice and physician characteristics can significantly affect physician usage of laboratory functionalities.

Keywords: Laboratory information system; Electronic health records; Ambulatory care

\section{Introduction}

Laboratory testing plays a critical role in the delivery of healthcare. According to Trepagnier [1], an estimated $90 \%$ of the clinical information in a patient record comes from a laboratory. Furthermore, as high as $70 \%$ of physician clinical decision-making relies on laboratory test results [2]. Laboratory information maximizes the effective delivery of care by allowing physicians and other health care professionals to make appropriate diagnostic and therapeutic decisions for patients. Therefore, using a laboratory information system and an EHR in meaningful ways to improve patient care quality is essential. Furthermore, assessing effective functionality of an EHR to ensure proper flow of laboratory test results and messages to physician offices is important. However, evidence reveals the flow of information from the LIS to the EHR is challenging and lacks appropriate functionality and meaningful use. Lin, et al. [3] reported difficulty accessing laboratory results as a significant contributor to lost laboratory results. In addition, Casalino et al. [4] highlighted partial laboratory medical records as potential causes of errors. Despite large investments in health information systems, laboratory information systems (LIS), especially systems that interface with EHRs, remain a poorly studied area [5].

This study explored the EHR interoperability and functional interconnectivity with the LIS. This study is particularly important because it provides a better understanding about the meaningful use of electronic laboratory services by ambulatory physicians, and greater knowledge of practice characteristics associated with this meaningful use.

\section{Literature Review}

\section{EHR meaningful use}

Adopting the definition of Robertson et al. [6], an EHR is described as a digital, longitudinal record of patient health records that allow an effective continuum of patient care. An EHR is only one aspect of the electronic health information process. Using the specific requirements embodied in the Health Information Technology for Economic and Clinical Health (HITECH) Act of 2009, meaningful use, defined as using an EHR in meaningful ways to manage patient care, to exchange health information in support of better care coordination, and to document quality measures [7] is an essential aspect of the EHR. Blumenthal, et al. [8] emphasized that HITECH was to promote adoption of the basic functions of the EHR and the use of the system by providers in meaningful ways to achieve significant improvement in care. The ability to interconnect with department or institution information systems is critical for the overall functionality and meaningful use of EHR. The quick and easy access for example, to laboratory results, patient clinical

*Corresponding author: Genita N Hyacinthe, AT Still University, College of Graduate Health Studies, 5850 E. Still Circle, Mesa, AZ 85206, Tel: 425-374-9373 E-mail: jwhyacinthe@comcast.net

Received September 03, 2018; Accepted September 24, 2018; Published October 06, 2018

Citation: Hyacinthe GN, Mathieson K (2018) Laboratory Information SystemElectronic Health Record Interconnection, Usage and Functionality in Ambulatory Care Settings. J Health Med Informat 9: 322. doi: 10.4172/2157-7420.1000322

Copyright: (c) 2018 Hyacinthe GN, et al. This is an open-access article distributed under the terms of the Creative Commons Attribution License, which permits unrestricted use, distribution, and reproduction in any medium, provided the original author and source are credited. 
histories, and important clinical messages, have the potential to improve health care quality.

Romano, et al. [9] conducted a retrospective analysis exploring the efficiency of EHR to physicians in clinical decision support (CDS). Using the National Ambulatory Medical Care Survey (NAMCS) data to measure quality of care in ambulatory medicine and the appropriate ordering of laboratory screening tests for urinary tract infections as a quality indicator, Romano, et al. [9] assessed the relationship between EHR usage and quality of care in outpatient physician practices. The authors reported variations in EHR usage and CDS in ambulatory care with a $17 \%$ usage rate and a $57 \%$ CDS rate and no significant association between usage functionality and quality care. Although general EHR usage was reported, direct LIS usage by physicians was not revealed. Romano, et al. [9] recognized their cross-sectional study design, the presence of possible confounding variables, and the probability of EHRbased technologies not consistently used, as limitations of the study.

\section{EHR-LIS interconnectivity and interoperability}

An LIS is designed to meet the unique needs and workflow in a laboratory and to integrate laboratory results with EHRs through an interface [10]. Effective display of laboratory results in the EHR enables physicians to manage and follow-up abnormal test results on patients in a timely fashion, key elements to improve health care quality and increase the number of meaningful users of an EHR-LIS. Staes et al. [11] recognized the lack of standardization in the reporting of laboratory results and the lack of fully functional electronic systems to report laboratory results to physicians as important factors contributing to delay in patient care.

Studies exploring effectiveness in EHR interconnection and data sharing capabilities often neglect to address the full incorporation of laboratory modules in an EHR. In addition, studies investigating the direct functional interconnection between the LIS and EHR are few, thereby limiting evidence-based information that contributes to better laboratory diagnosis and better patient care. Using focus group interviews and individual interviews of 29 practicing physicians, Goldman, et al. [12] explored physician attitudes towards concerns with laboratory monitoring, and opinions on the potential effects of an EHRbased computerized clinical decision support system on care efficiency and quality. Goldman et al. [12] reported physician views of laboratory monitoring as a crucial aspect of the health care delivery system, although lack of standardization was recognized by all participants.

In a later study, Rao et al. [13] administered a nationally representative survey to practicing physicians identified at random from the American Medical Association Physician Masterfile to assess EHR availability, usage, and functionalities. Rao et al. [13] reported $13 \%$ of 2,729 physicians surveyed who practiced in group of 11 or more were using the EHR full functionality compared to a $2 \%$ rate for practices with one or two physicians. Because EHR adoption by non-responders might have been different enough to significantly affect the outcomes of Rao et al's study, its $62 \%$ response rate could be considered as a limitation. Xierali, et al. [14] revealed a doubling of EHR adoption by family physicians since 2005 , reaching $68 \%$ in 2011 . However, Xierali, et al. [14] also called for further monitoring to ensure effective data exchange capabilities necessary for health care. Research is needed to fill this gap. In this study, NAMCS data were used to first explore the level of meaningful use of laboratory services by ambulatory care physicians, then to investigate the association between specialty type, practice type, ownership status, and geographical region with this meaningful usage.

\section{Methods}

This was a correlational study using 2012 NAMCS data. We conducted a retrospective, cross-sectional analysis to determine the proportion of ambulatory care physicians who used the EHR meaningfully to access patient data from the LIS. The aim of this study was to explore the use of electronic laboratory services through the EHR-LIS interconnectivity to access patient laboratory data in meaningful way. This study was further used to evaluate the relationship between practice characteristics and meaningful usage of laboratory functionalities.

\section{Data Analysis}

All data were analyzed using IBM SPSS Statistics Version 23.0. Frequencies and percentages were used to characterize physician practices by type, specialty, ownership status, location, geographical region, and to determine routine usage of an EHR. Meaningful usage of medical laboratory services by ambulatory care physicians was defined by the following specific functionality measures: Electronic ordering of laboratory tests, reviewing, overtime graphing, and sharing of laboratory test results. Meaningful usage functionalities were recoded into binary variables. Descriptive statistics were first used to determine the frequency and percentage of physician usage of each meaningful usage function. Logistic regression was then performed to define the physician practice characteristics or factors associated with meaningful usage of the EHR and the laboratory information system (LIS) by ambulatory care physicians.

Physician access to laboratory results were measured by the presence of computerized capabilities in the practices, such as electronic ordering and review of test results, electronically sharing of laboratory results, and patient laboratory results graphing overtime. Furthermore, contributing factors were assessed by examining physician characteristics, such as types of specialty to include primary care, surgical care, and medical care physicians. Practice characteristics, such as type (solo, non-solo), ownership status (full-owner, part-owner, employee, contractor), regions, and Metropolitan Area were also explored.

To operationalize the study concept, the dependent variables EHR meaningful usage functionalities of LIS by outpatient physicians were defined as the proportion of physicians who access the EHR to order laboratory tests, to electronically review laboratory test results, to electronically graph laboratory test results over time, to electronically share patient laboratory test results with affiliated and non-affiliated hospitals, and with ambulatory providers inside and outside practice groups. Each usage aspect was measured at a ratio level by determining the general EHR usage among all physicians, then determining the usage proportion of each LIS functionality. To explore whether associations existed between practice characteristics and meaningful usage of the EHR-LIS, seven logistic regression models were applied, one for each meaningful usage function. The relationship between meaningful usage and practice factors was modeled to evaluate change in access to laboratory data. These analyses were restricted to physicians who reported using the EHR on a routine basis.

\section{Results}

A total of 76,330 ambulatory care physicians participated in the 2012 NAMCS. Participants who did not meet the inclusion criterion, which required routine usage of an EHR, were excluded. This exclusion resulted in 44,296 physician responses for analysis. The largest group of respondents were physicians practicing in the primary care specialty $(20,444 ; 46.2 \%)$ followed by medical care $(14,679 ; 33.1 \%)$, and surgical 
Citation: Hyacinthe GN, Mathieson K (2018) Laboratory Information System-Electronic Health Record Interconnection, Usage and Functionality in Ambulatory Care Settings. J Health Med Informat 9: 322. doi: 10.4172/2157-7420.1000322

Page 3 of 5

care $(9,173 ; 20.7 \%)$. Nearly $80 \%$ of physicians worked in non-solo practices. The proportion of employed physicians and independent practice owners (full or part-owners) was divided about evenly. More of those ambulatory practices were in the South region of the country (38.0\%), while practices in the Midwest and West regions were equally distributed. Physician practices were predominantly in metropolitan statistical areas (85.5\%). Table 1 summarizes characteristics of survey participants who reported using an EHR on a regular basis by specialty, practice type, practice ownership status, and geographical location. With the study's large sample size, no association was expected between predictor variables. However, prior to regression analysis, variance inflation factors were assessed to confirm the absence of Multicollinearity between predictors. All variance inflation factors were within acceptable ranges $(<5.0)[15]$.

\section{Frequency of meaningful usage functionalities}

Frequency of meaningful usage functions varied greatly among ambulatory physicians. Of the 44,296 ambulatory physicians who routinely used an EHR, 35,985 reported the capability to order laboratory tests $(81.2 \%)$. However, almost $25 \%$ of physicians chose either not to use this function on a routine basis, kept the function on without using it, or chose to have it turned off. Nevertheless, most physicians reported routine usage (Table 2). Over $80 \%$ of physicians reported using the EHR and the Laboratory Information System interface to review patient laboratory test results. Evaluating patient laboratory result trends over time is important for physicians to monitor clinically significant changes from patient baseline values. More than $60 \%$ of ambulatory physicians reported using the EHR-LIS graphing function. Ambulatory physicians were significantly more likely to electronically share patient laboratory results with hospitals with which they were affiliated and with other ambulatory care providers inside their practice group (Table 2). Table 2 shows the numbers and percentages of physicians who reported using the following medical laboratory services in meaningful

\begin{tabular}{|c|c|}
\hline Characteristics & Participantsn (\%) \\
\hline \multicolumn{2}{|l|}{ Types of Specialty } \\
\hline $\begin{array}{l}\text { Primary care } \\
\text { physicians }\end{array}$ & $20,444(46.2)$ \\
\hline $\begin{array}{l}\text { Surgical care } \\
\text { physicians }\end{array}$ & $9,173(20.7)$ \\
\hline $\begin{array}{l}\text { Medical care } \\
\text { physicians }\end{array}$ & $14,679(33.1)$ \\
\hline \multicolumn{2}{|l|}{ Type of Practice } \\
\hline Non-solo & $34,552(78.0)$ \\
\hline Solo & $9734(22.0)$ \\
\hline \multicolumn{2}{|l|}{$\begin{array}{l}\text { Ownership Status of } \\
\text { Physicians }\end{array}$} \\
\hline Full-owner & $12,127(27.4)$ \\
\hline Part-owner & $14,375(32.5)$ \\
\hline Employee & $16,053(36.2)$ \\
\hline Contractor & $1,379(3.1)$ \\
\hline \multicolumn{2}{|l|}{ Regions of Practices } \\
\hline Northeast & $4,778(10.8)$ \\
\hline Midwest & $11,257(25.4)$ \\
\hline South & $16,838(38.0)$ \\
\hline West & $11,423(25.8)$ \\
\hline \multicolumn{2}{|l|}{$\begin{array}{l}\text { MSA (Metropolitan Area) } \\
\text { Status of Physician location }\end{array}$} \\
\hline MSA & $37,855(85.5 \%)$ \\
\hline Non-MSA & $6441(14.5 \%)$ \\
\hline
\end{tabular}

Table 1: Study participant characteristics $(N=44,296)$. way: Electronic ordering, reviewing, overtime graphing, and sharing of laboratory test results.

\section{Factors associated with meaningful usage}

Logistic regression analysis was conducted using physician practice specialty, type, region, metropolitan statistical area, and ownership status as independent variables. Meaningful usage of medical laboratory data by ambulatory physicians was strongly associated with several physician practice characteristics. When levels of ordering laboratory tests and receiving test results electronically were predicted, type of physician practice (odd ratio $[\mathrm{OR}]=1.79$, confidence interval $[\mathrm{CI}]=1.68$ 1.91), geographical region of physician practices $(\mathrm{OR}=1.06, \mathrm{CI}=1.03$ 1.09), and ownership status ( $\mathrm{OR}=1.19, \mathrm{CI}=1.15-1.22)$ indicated positive relationships and strong predictors. When electronic capability of reviewing laboratory results was predicted, positive relationships were observed with type of physician practice $(\mathrm{OR}=2.64, \mathrm{CI}=2.49-2.81)$, metropolitan statistical area of physician practice $(\mathrm{OR}=1.80, \mathrm{CI}=1.65$ 1.96) and ownership status ( $\mathrm{OR}=1.38, \mathrm{CI}=1.33-1.42)$, while physician specialty and practice region had negative associations. EHR-LIS review of laboratory results was positively related with practice type $(\mathrm{OR}=2.64$, $\mathrm{CI}=2.49-2.81)$, metropolitan statistical area $(\mathrm{OR}=1.80, \mathrm{CI}=1.65-1.96)$, and ownership status $(\mathrm{OR}=1.38, \mathrm{CI}=1.33-1.42)$. All predictor variables except for specialty type showed positive association with physician usage of electronic graphing of patient results over time. In predicting sharing of laboratory results with affiliated hospitals and ambulatory care providers inside the practice group, positive associations were showed with all the predictor variables except for specialty type, which demonstrated a negative relationship. Sharing laboratory results with non-affiliated hospitals and providers outside the practice group, on the other hand had a positive association with specialty type $(\mathrm{OR}=1.06$, $\mathrm{CI}=1.02-1.10$ and $\mathrm{OR}=1.14, \mathrm{CI}=1.10-1.18)$. Table 3 presents the logistic

\begin{tabular}{|c|c|}
\hline Meaningful Use Functionalities & Participants \\
\hline Electronic Ordering of Laboratory Tests & $n=35,985$ \\
\hline Used Routinely, n (\%) & $27,436(76.2)$ \\
\hline $\begin{array}{c}\text { Not Used; Not Used Routinely; or Turned } \\
\text { off, } n(\%)\end{array}$ & $8,549(23.8)$ \\
\hline Electronic Review of Laboratory Test Results & $n=43,864$ \\
\hline Used Routinely, n (\%) & $36,672(83.6)$ \\
\hline $\begin{array}{c}\text { Not Used; Not Used Routinely; or Turned } \\
\text { off, } n(\%)\end{array}$ & $7,192(16.4)$ \\
\hline Graphing of Laboratory Results Over Time & $n=33,538$ \\
\hline Used Routinely, n (\%) & $21,504(64.1)$ \\
\hline $\begin{array}{c}\text { Not Used; Not Used Routinely; or Turned } \\
\text { off, } n(\%)\end{array}$ & $12,034(35.9)$ \\
\hline $\begin{array}{l}\text { Electronic Sharing of Laboratory Results with } \\
\text { Affiliated Hospitals }\end{array}$ & $n=23,388$ \\
\hline Sharing, $\mathrm{n}(\%)$ & $17,722(75.8)$ \\
\hline Not Sharing, n (\%) & $5,666(24.2)$ \\
\hline $\begin{array}{l}\text { Electronic Sharing of Laboratory Results with } \\
\text { Ambulatory Providers inside Group }\end{array}$ & $n=23,888$ \\
\hline Sharing, $\mathrm{n}(\%)$ & $17,464(74.7 \%)$ \\
\hline Not Sharing, $\mathrm{n}(\%)$ & $5,924(25.3 \%)$ \\
\hline $\begin{array}{l}\text { Electronic Sharing of Laboratory Results with Non- } \\
\text { affiliated Hospitals }\end{array}$ & $n=23,388$ \\
\hline Sharing, n (\%) & $4,883(20.9 \%)$ \\
\hline Not Sharing, n (\%) & $18,505(79.1 \%)$ \\
\hline $\begin{array}{l}\text { Electronic Sharing of Laboratory Results with } \\
\text { Ambulatory Providers outside Group }\end{array}$ & $n=23,388$ \\
\hline Sharing, $\mathrm{n}(\%)$ & $7,434(31.8 \%)$ \\
\hline Not Sharing, n (\%) & $15,954(68.2 \%)$ \\
\hline
\end{tabular}


Citation: Hyacinthe GN, Mathieson K (2018) Laboratory Information System-Electronic Health Record Interconnection, Usage and Functionality in Ambulatory Care Settings. J Health Med Informat 9: 322. doi: 10.4172/2157-7420.1000322

Page 4 of 5

\begin{tabular}{|c|c|c|c|c|c|}
\hline & $\begin{array}{c}\text { Physician Specialty: OR } \\
(95 \% \mathrm{Cl})\end{array}$ & $\begin{array}{r}\text { Practice Type: } \text { OR (95\% } \\
\text { CI) }\end{array}$ & $\begin{array}{l}\text { Practice Region: OR }(95 \% \\
\mathrm{CI})\end{array}$ & $\begin{array}{l}\text { Metropolitan Statistical } \\
\text { Area (MSA):OR }(95 \% \mathrm{CI})\end{array}$ & $\begin{array}{l}\text { Ownership Status: } \\
\text { OR }(95 \% \mathrm{Cl})\end{array}$ \\
\hline $\begin{array}{c}\text { Electronic-Ordering of } \\
\text { Lab Tests }\end{array}$ & $0.85(0.83-0.88)$ & $1.79(1.68-1.91)$ & $1.06(1.03-1.09)$ & $0.99(0.92-1.06)$ & $1.19(1.15-1.22)$ \\
\hline $\begin{array}{l}\text { Electronic-Reviewing of } \\
\text { Lab Results }\end{array}$ & $0.69(0.67-0.71)$ & $2.64(2.49-2.81)$ & $0.96(0.94-0.99)$ & $1.80(1.65-1.96)$ & $1.38(1.33-1.42)$ \\
\hline $\begin{array}{l}\text { Electronic-Graphing of } \\
\text { test results overtime }\end{array}$ & $0.98(0.96-1.01)$ & $1.74(1.63-1.85)$ & $1.13(1.10-1.16)$ & $1.50(1.40-1.60)$ & $1.13(1.10-1.16)$ \\
\hline $\begin{array}{l}\text { E-Sharing of test results } \\
\text { with affiliated hospitals }\end{array}$ & $0.89(0.86-0.92)$ & $1.38(1.27-1.50)$ & $1.13(1.09-1.17)$ & $1.28(1.17-1.40)$ & $1.23(1.18-1.28)$ \\
\hline $\begin{array}{l}\text { E-Sharing of test results } \\
\text { with physicians inside } \\
\text { practice }\end{array}$ & $0.87(0.84-0.90)$ & $2.42(2.23-2.62)$ & $1.15(1.11-1.18)$ & $1.25(1.14-1.37)$ & $1.44(1.38-1.49)$ \\
\hline $\begin{array}{c}\text { E-Sharing of test results } \\
\text { with non-affiliated } \\
\text { hospitals }\end{array}$ & $1.06(1.02-1.10)$ & $1.22(1.11-1.34)$ & $0.96(0.93-0.99)$ & $1.38(1.26-1.50)$ & $0.91(0.87-0.95)$ \\
\hline $\begin{array}{l}\text { Electronic sharing of test } \\
\text { results with physicians } \\
\text { outside practice }\end{array}$ & $1.14(1.10-1.18)$ & $0.79(0.73-0.85)$ & $0.94(0.91-0.96)$ & $1.20(1.11-1.30)$ & $0.77(0.74-0.80)$ \\
\hline
\end{tabular}

Table 3: Logistic regression results predicting meaningful use functionalities.

regression models obtained with OR, and 95\% confidence interval values for each predictor variable. Factors that were most frequent facilitators of meaningful usage of the EHR-LIS were practice type, and ownership status.

\section{Discussion}

Our goal was to determine usage level of laboratory functions in ambulatory care physicians who routinely used an EHR and factors associated with usage. Our results indicate that in physicians who use an EHR routinely, a majority used an EHR-LIS to meaningfully access laboratory services. More than $75 \%$ of practices used an EHR-LIS to electronically order laboratory tests and access patient laboratory test results. We also found strong statistical associations between all examined factors and the use of EHR-LIS functionalities. Practice type, region, metropolitan statistical area, and ownership status exhibited significant positive relationships with physicians electronically graphing patient laboratory results overtime and sharing results with affiliated hospitals and with ambulatory care providers in their practice groups. On the other hand, practice region and ownership status were negatively associated with laboratory results sharing with nonaffiliated hospitals and providers outside practice groups. Rao et al. [13] identified practice size as a significant influence on routine usage of the EHR full functionality. Our study indicates a similar influence on the meaningful use of the EHR-LIS. Practice types (solo/non-solo) had a strong positive association with all EHR-LIS functionalities examined, aside from sharing laboratory results with ambulatory care physicians outside practice groups.

Physicians were more likely to share patient laboratory results with physicians in their practice groups and affiliated hospitals. While these findings were not surprising, they emphasize an area that needs more focus due to its essential role in maintaining patient healthcare continuum and care quality. Although the large sample size and narrow $\mathrm{CI}$ increase the accuracy and generalization of our results, the study has its limitations. One limitation of the study was that it is retrospective, therefore, temporal relationships might be difficult to assess. Another limitation of the study is that even though meaningful use assessment was done using laboratory functions that are considered important, there are other valuable functions, such as flagging of critical results, and flagging of results with significant differences that are worth exploring. Future research should further investigate the causal relationship between meaningful usage of the EHR-LIS and ambulatory care physicians.

\section{Conclusion}

The vital role of clinical laboratory testing in healthcare delivery cannot be understated. Patient care providers, including physicians in ambulatory care practices rely on laboratory test results to make clinical decisions regarding patients. The results of this study not only provide objective information about the level of meaningful usage of laboratory services, they also reveal factors that positively or negatively influence this meaningful usage. By understanding more about this process, researchers can increase usage and functionality of the LISEHR interconnection by providing evidence-based information to strengthen clinical decision-making, and the overall quality of care.

\section{Acknowledgement}

I would like to acknowledge that this work was completed as part of my doctoral study at A.T. Still University (ATSU).

\section{Conflict of Interest}

The author declares no conflict of interest regarding the publication of this manuscript.

\section{References}

1. Trepagnier $T$ (2013) What $P O L$ need to know: Meeting "meaningful use" criteria for EHR incentives. Medical Laboratory Observer pp. 24-26.

2. Molinaro R, Winkler A, Kraft C, Fantz C, Stowell S, et al. (2012) Teaching laboratory medicine to medical students: implementation and evaluation. Arch Pathol Lab Med 136: 1423-1429.

3. Lin J, Dunn A, Moore C (2006) Follow-up of outpatients test results: A survey of house-staff practices and perceptions. Am J Med Qual 21: 178-184.

4. Casalino P, Dunham D, Chin M, Bielang R, Kistner E, et al. (2009) Frequency of failure to inform patients of clinically significant outpatient test results. Arch Intern Med 169: 1123-1129. 
Citation: Hyacinthe GN, Mathieson K (2018) Laboratory Information System-Electronic Health Record Interconnection, Usage and Functionality in Ambulatory Care Settings. J Health Med Informat 9: 322. doi: 10.4172/2157-7420.1000322

Page 5 of 5

5. Coiera E (2006) Communication systems in healthcare. Clin Biochem Rev 27: 89-98.

6. Robertson A, Cresswell K, Takian A, Petrakaki D, Crowe S, et al. (2010) Implementation and adoption of nationwide electronic health records in secondary care in England: Qualitative analysis of interim results from a prospective national evaluation. BMJ 341: 1-12.

7. Henricks W (2011) Meaningful use of electronic health records and its relevance to laboratories and pathologists. J Pathol Inform 2: 1-15.

8. Blumenthal D, Tavenner M (2010) The "meaningful use" regulation for electronic health records. N Engl J Med 363: 501-504.

9. Romano M, Stafford R (2011) Electronic health records and clinical decision support systems. Arch Intern Med 171: 897-903.

10. Wilkerson M, Henricks W, Castellani W, Whitsit M, Sinard J (2015) Management of laboratory data and information exchange in the electronic health record.
Arch Pathol Lab Med 139: 319-327.

11. Staes C, Evans S, Rocha B, Sorensen J, Huff S, et al. (2008) Computerized alerts improve outpatient laboratory monitoring of transplant patients. J Am Med Inform Assoc 15: 324-332.

12. Goldman R, Soran C, Hayward G, Simon S (2010) Doctors' perceptions of laboratory monitoring in office practice. J Eval Clin Pract 16: 1136-1141.

13. Rao S, DesRoches C, Donelan K, Campbell E, Miralles P, et al. (2011) Electronic health records in small physician practices: availability, use, and perceived benefits. J Am Med Inform Assoc 18: 271-275.

14. Xierali I, Hsiao C, Puffer J, Green L, Rinaldo J, et al. (2013) The rise of electronic health record adoption among family physicians. Ann Fam Med 11: 14-19.

15. Stine R (1995) Graphical interpretation of variance inflation factors. Am Stat 49: $53-56$ 